\title{
ANATOMICAL STUDIES ON THE ARTERIAL SUPPLY OF THE EYE IN THE ONE- HUMPED CAMEL (CAMELUS DROMEDARIUS)
}

\author{
Nawal. A. Noor ${ }^{1}$, Samah. H. El-bably *2. \\ ${ }^{1}$ Lecturer of Anatomy \& Embryology, Faculty of Veterinary Medicine, Cairo University, Egypt. \\ *2 Assistant Professor of Anatomy \& Embryology, Faculty of Veterinary Medicine, Cairo University, \\ Egypt.
}

\section{ABSTRACT}

Aim: This work focused on the arteries supplying the eye of the one-humped camel. The origin; course and distribution of the arteries were studied, that's helped in the field of comparative veterinary anatomy and surgical operations.

Materials and Methods: Six heads of camels used in this study, the heads were cannulated through the common carotid artery and washing with the normal saline solution. Dissolve a 50gm lead oxide powder in a $150 \mathrm{ml}$ solution of the red gum milk latex and the common carotid artery was injected. Four heads were undergoing the fine dissection to demonstrate the arterial supply of the eye and other two heads were used for X-rays purposes. The data were photographed using Sony camera 14 Megapixel, 5X.

Results: The eye of the camel was supplied through the external ophthalmic artery, external ethmoidal artery, in addition to the malar artery, the maxillary tubercular artery and angular artery of the infraorbital artery.

Conclusion: this study gave off a clear anatomical data about the arteries of the eye of dromedary camel that helped the surgeon in the surgical interference.

KEY WORDS: Anatomy, Arteries, Eye, Camel, External ophthalmic artery.

Address for Correspondence: Dr. Samah. H. El-bably, Assistant Professor of Anatomy \& Embryology, Faculty of Veterinary Medicine, Cairo University, Egypt. E-Mail: drsamah.elbably@yahoo.com

Access this Article online

Quick Response code

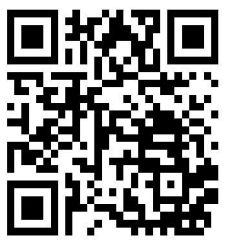

DOI: $10.16965 /$ ijar.2018.118

Journal Information

International Journal of Anatomy and Research

ICV for 2016
90.30 $\begin{gathered}\text { ISSN (E) 2321-4287 | ISSN (P) 2321-8967 } \\ \text { https://www.ijmhr.org/ijar.htm } \\ \text { DOI-Prefix: https://dx.doi.org/10.16965/ijar }\end{gathered}$

Article Information

Received: 15 Jan 2018

Peer Review: 15 Jan 2018

Revised: None
Accepted: 12 Feb 2018

Published (O): 05 Mar 2018

Published (P): 05 Mar 2018

\section{INTRODUCTION}

The dromedary camels (one-humped camels) represented about $94 \%$ of the population of camels which distributed all over the world, commonly in the Middle East and the Northern Africa [1].

The kind of literatures on the blood supply of the eye in the animals were few, especially in the camel. The eye was an important organ useful for animal life, that's helped in satisfying the requirement of an animal. Although some authors as [2-7] worked on the eye of the camel, but at this time no any research had a clear photographs clarify the distribution of the arterial supply of the eye and only some drawing and diagrams present in the online published researches so that these study considered a document discussed the origin, course and distribution of the arteries that supplied the eye of the dromedary camel.

\section{MATERIALS AND METHODS}

Six heads of camels used in the current study, Four heads washed through the common carotid artery cannulation by using a warm normal saline solution $(0.9 \%)$, then the heads injected with $10 \%$ formalin solution (10\%) and placed in 
a plastic container, had a diluted formalin solution (formalin $10 \%$, glycerin $1 \%$, and phenol $4 \%$ ) for 2-3 days. Then injected with gum milk latex colored red by Rotring Ink for arterial supply investigation and left for 3 days in the formalin container before the routine dissection. The other two fresh heads injected with a 50gm lead oxide powder dissolved in a $100 \mathrm{ml}$ solution of red gum milk latex for $X$ - rays purposes, the exposure factors were $100 \mathrm{~cm}$. FFD, with $15 \mathrm{mAs}$ and $55 \mathrm{KV}$. The heads were dissected and photographed using Sony digital camera 14 megapixel, $5 \mathrm{X}$, the results compared with the other domestic animals according to the [8].

\section{RESULTS}

The arterial blood supply of eye was mainly derived from the internal maxillary artery, via; the external ophthalmic artery, rostral epidural rete mirabile, external ethmoidal artery, in addition to some branches of the infraorbital artery.

Maxillaris: The maxillary artery was the direct continuation of the external carotid artery at the medial aspect of the medial pterygoid muscle, it gave off a several branches which supplied the masseter, temporal, pterygoids muscles, meninges, hard palate, soft palate and the eye. The eye was supplied through the external ophthalmic, external ethmoidal, and infraorbital arteries (Plate 1, fig. 6/1).

Ophthalmica Externa: The external ophthalmic was the major artery of the eye, emerged from the dorsal aspect of the maxillary artery, at the orbitorotundum foramen, just rostral to the coronoid process of the mandible. It passed dorsally and rostrally with the corresponding nerve entered the periorbit, medial to the maxillary nerve, supplying the eye with supraorbital artery, dorsal oblique muscular branch, rostral rete mirabile and Zygomaticotemporal A., which distributed along the lateral wall of the ocular muscles, and then it entered deeply under the retractor ocular muscle. It was detached the posterior long ciliary arteries and central retinal artery (Plate 1, 2, Fig $6 / 2$ ).

Supraorbitalis: The supraorbital artery arose from the external ophthalmic artery, it passed dorsally and rostrally along the dorsal rectus muscle in zigzag manner, close to the lateral wall of the frontal bone, reaching to the supraorbital process of the skull, supplying the supraorbital region (Plate 1, 2, Fig $6 / 7$ ). During its course, it was anastomosed with the dorsal oblique muscular artery (Fig. 8/8'), and anastomosed with the external ethmoidal artery at the supraorbital foramen (Plate $3 / 14^{\prime}$ ).

Ramus muscularis obliquus dorsalis: The dorsal oblique muscular branch was a large muscular branch, arose from the external ophthalmic artery (Plate $2 / 8$ ), it entered between the ventral margin of the dorsal rectus muscle and the lateral rectus one, and continued rostrally and dorsally reaching to the lateral border of the dorsal oblique muscle and supplied it. In $20 \%$ of cases, it was originated from the external ethmoidal artery (Plate $3 / 8$ ), and anastomosed with the supraorbital artery (Plate $3 / 8^{\prime}$ ).

Ramus zygomaticotemporalis: The zygomaticotemporal artery was the largest branch emerging from the external ophthalmic artery; it passed rostrally and laterally in between the dorsal rectus muscle and lateral rectus one, accompanies the corresponding nerve. It gave off 2-3 lacrimal branches and then perforated out through the periorbita at the caudal surface of the supraorbital process to be terminated by two branches lateral superior palpebral and lateral inferior palpebral branches. Some muscular branches detaching from those branches supplying the skin of the frontal region and frontoscatularis muscle (Plate 1, 2, Fig 6 /9).

Lacrimalis: The lacrimal artery arose with the emergence of zygomaticotemporal artery from the external ophthalmic artery, passed along the lateral rectus muscle (Plate $1 / 10)$. Also The lacrimal gland was supplied with 3-4 branches arose directly from the zygomaticotemporal artery, one branch passed along the circumference of the lacrimal gland (Plate 1/ $\left.10^{\prime}\right)$, and 2-3 branches detached at the dorsal border of the lateral rectus muscle (Plate $2 / 10^{\prime}$ ).

Palpebralis superior lateralis: The lateral superior palpebral artery was one of the two terminations of the zygoma ticotemporal artery, it was penetrated the periorbita, it passed rostrally, along the dorsal margin of the eye, to be entered the superior eyelid supplying it and the frontal region. It was anastomosed 
with the medial superior palpebral artery of the malar artery (Plate $1 / 11$ ).

Palpebralis inferior lateralis: The lateral inferior palpebral artery was the second termination as the superior one, but it passed rostrally toward the ventral margin of the eye to be entering the inferior eyelid. It was anastomosed with the medial inferior one of the malar artery (Plate $1 / 12$ ).

Rami musculares: 4-6 muscular branches arose from the lateral superior and lateral inferior arteries after penetration the periorbita, ramified to the skin of the frontal region and the frontoscatularis muscle of ear (Plate $1 / 13$ ).

Rami rete mirabile epidurale rostrale: The rostral epidural rete mirabile (Plate 1 , Fig $6 / 5$ ) were about 5-6 branches arose from the dorsal wall of the external ophthalmic artery by a common trunk. Also 2-3 branches (Plate 1, 2, Fig 6/5') detached from the dorsal wall of the maxillary artery, rostral to the external ophthalmic artery, these rostral branches surrounded the maxillary nerve laterally and medially forming epidural rete mirabile. These branches passed cranially at the dorsal wall of the origin of the dorsal rectus muscle, then entered deeply between this muscle and retractor oculi muscle forming ophthalmic rete mirabile (Plate 1,4 , fig $6 / 6$ ).

\section{Ophthalmic rete mirabile:}

The ophthalmic rete mirabile (Plate 1, 4, Fig 6 /6) produced about of 3-5 uniting branches, it passed cranially deeply between the ventral part of the dorsal rectus muscle and retractor oculi muscle, and it gave off the deep part of the external ophthalmic artery and central retinal artery. Then the external ophthalmic coursed along the medial aspect of the optic nerve, at the rostral part of the optic nerve, detaching the long posterior ciliary arteries (Aa. Ciliares posteriors longae) and short posterior ciliary arteries (Aa. Ciliares posteriors breves). The posterior long ciliary arteries were the medial artery and lateral one.

The medial long posterior ciliary artery passed craniomedially along the optic nerve and entered the eyeball from the posterior end (Plate 4 /24). The lateral long posterior ciliary artery passed craniolaterally and entered the eyeball from the posterior end (Plate $4 / 25$ ).
The short posterior ciliaries arteries were about 4-6 branches, also medial and lateral branches, detaching from the long ciliary arteries, distributed around the optic nerve to enter the posterior pole of the eyeball (Plate $4 / 26$ ).

In half of cases the ophthalmic rete mirabile gave off the medial, lateral long ciliary arteries and the external ophthalmic artery, The lateral long ciliary artery anastomosed with the external ophthalmic, then crossed from medial side to lateral side of the optic nerve, the medial one passed craniomedially and gave off the central retinal (Plate 4 /23). A muscular branch arose from the medial long ciliary artery, also distributed to choroid (Plate 4 /27).

Centralis retinae: The central retinal artery arose from the ophthalmic rete mirabile, passed along the medial aspect of the optic nerve, under the medial face of the retractor oculi muscle, it entered the optic nerve and terminated by dividing into several branches supplying the choroids. Also in half of specimens, it originated from the medial posterior long ciliary artery (Plate 4 /23).

Ethmoidalis Externa: The external ethmoid artery emerged from the dorsal aspect of the maxillary artery, rostral to emerging of epidural rete mirabile branches (Plate 2, 3, Fig $6 / 14$ ). It distributed within the periorbita at the ventral aspect of the ocular muscles, it divided into two branches distributed on each side of the ventral rectus muscle until reach to the ventral oblique muscle and supplying them. In $20 \%$ of cases, it gave off a branch turn laterally to reach the lateral border of the dorsal oblique muscle supplying it (Plate $3 / 8$ ), and anastomosed with the supraorbital artery (Plate $3 / 8^{\prime}$ ). It also anastmosed with the supraorbital artery at the supraorbital foramen (Plate $3 / 14^{\prime}$ ).

Infraorbitalis: The infraorbital artery was the direct continuation of the maxillary artery within the infraorbital canal, it gave off the malar artery, maxillary tubercular artery and then left the infraorbital canal through the infraorbital foramen, accompanied the infraorbital nerve, and detaching the angular artery of the eye (Plate 3, $6 / 15$ ).

Malaris: The malar artery was emerged from the infraorbital artery, at the level of the maxillary 

DROMEDARIUS).

Plate (1): A photograph showing the branches of the external ophthalmic artery of the left eye of the camel. A- Lateral view, B- Zoom in branches, C- Caudal view, DDorsal view.

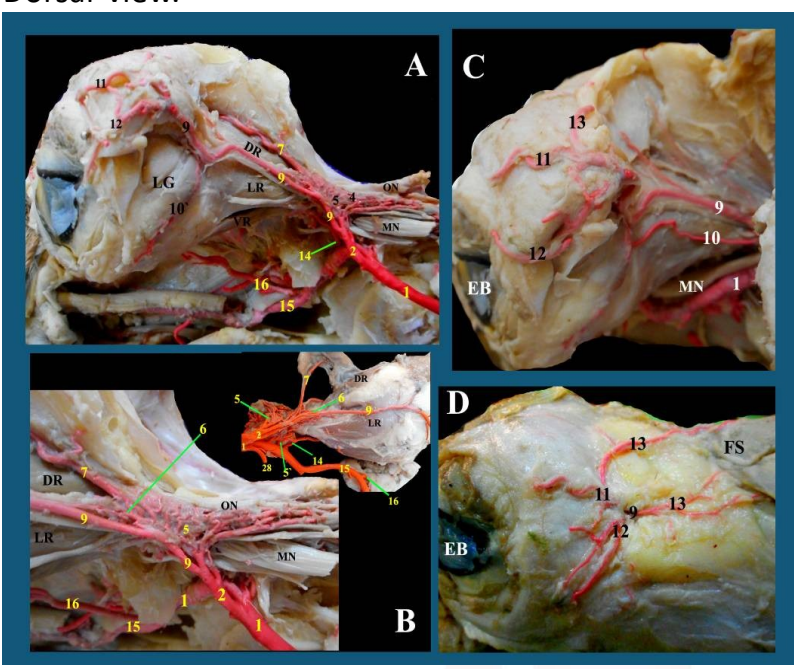

1- Maxillary A., 2- External ophthalmic A.,4- Epidural rete mirabile, 5- Rostral epidural rete mirabile, 6- Ophthalmic rete mirabile, 7- Supraorbital A., 9- Zygomaticotemporal A., 10- Lacrimal branch, 11Lateral superior palpebral A., 12- Lateral inferior palpebral A., 13- Muscular branches, 14- External ethmoidal A., 15-Infraorbital A, 16- Malar A. DR- Dorsal rectus $M$, LR- Lateral rectus $M$, LG- Lacrimal gland, EB- Eye ball, MA- Maxillary N, FS- Frontoscutularis M.
Plate (2): A photograph showing the branches of the external ophthalmic artery of the eye of the camel. A - Left lateral view, B- Left dorsal view, C- Right lateral view, D-Right ventral view.

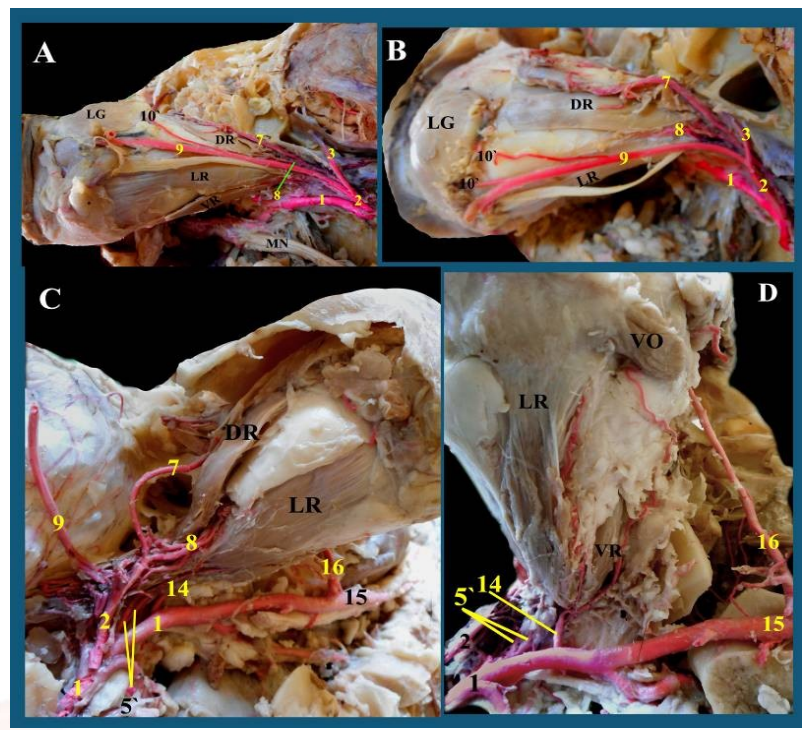

1- Maxillary A., 2- External ophthalmic A., 3- Temporal branch, 5- Epidural rete mirabile, 7- Supraorbital A, 8- Dorsal oblique branch, 9- Zygomaticotemporal A., 10'- Lacrimal branch, 14- External ethmoidal A, 15- Infraorbital A, 16- Malar A. DR- Dorsal rectus M, LRLateral rectus $M$, VR- Ventral rectus M., LG- Lacrimal gland.

Plate (3): A photograph showing the branches of the dorsal oblique and supraorbital arteries of the eye of the camel A \& C- Left dorsal view, B- Right dorsal view, D- Left caudal view, E- Left medial view.

1- Maxillary A., 2- External ophthalmic A.,

5- Epidural rete mirabile, 7- Supraorbital A.,

8- Dorsal oblique branch, 8'- Anastmosing branch, 9- Zygomaticotemporal A.,

14- External ethmoidal A, 14'- Anastomosing branch, 15- Infraorbital A., 16- Malar A, 17- Artery of third eyelid, 18- Medial superior palpebral A., 19- Medial inferior palpebral A., 21- Maxillary tubercular A. DO- Dorsal oblique M.,DR- Dorsal rectus $M$, MR- Medial rectus M, LG- Lacrimal gland, FB- Frontal bone, F- Supraorbital foramen.

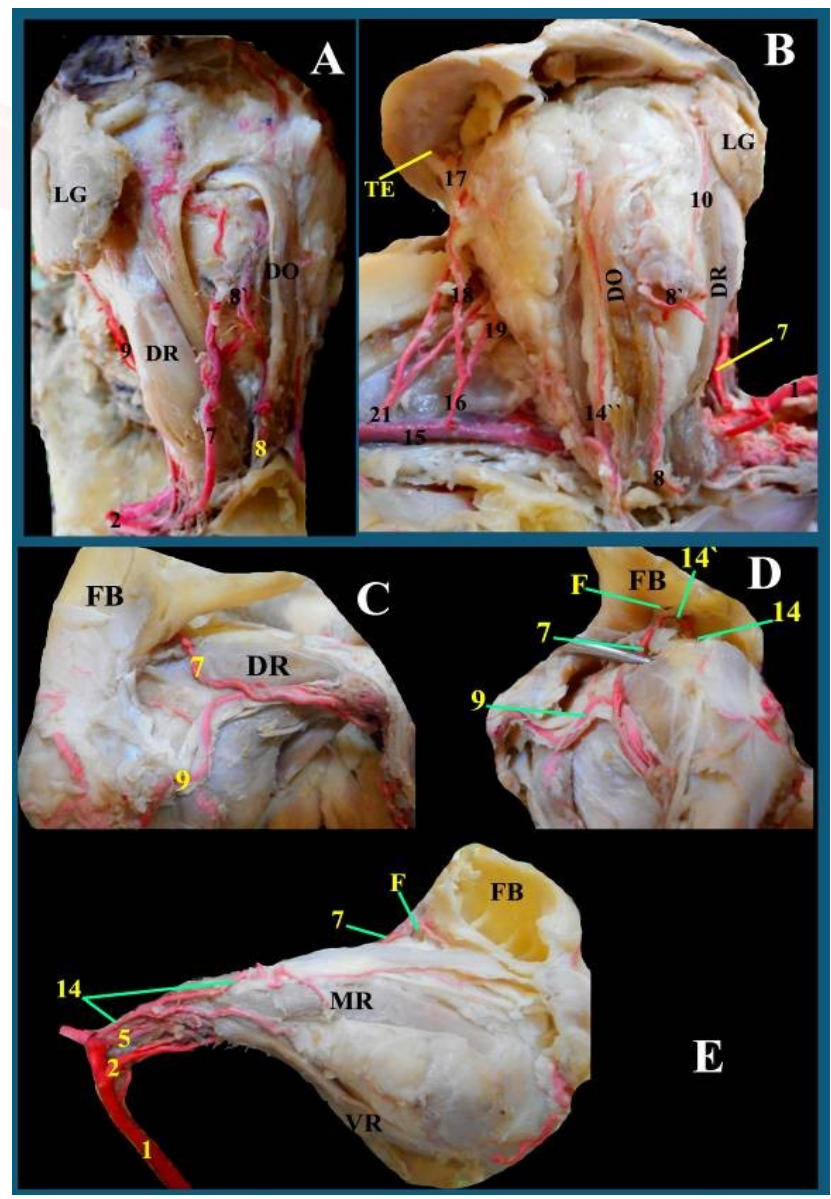


Plate (4): A photograph showing the branches of the deep part of the external ophthalmic artery of the eye of the camel. A- Right dorsal view, B \& C- the branches of ophthalmic rete mirabile.

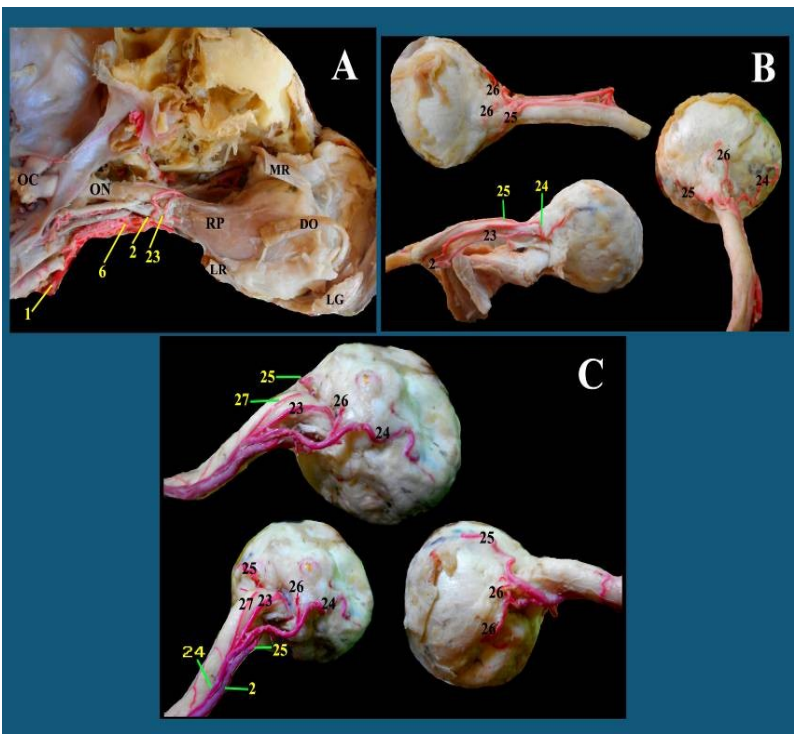

1- Maxillary A., 2- External ophthalmic A. (deep part), 6- Ophthalmic rete mirabile, 23- Central retinal artery, 24- Medial long posterior ciliary A., 25- Lateral long posterior ciliary A, 26- Short ciliaries arteries, 27- Muscular branch. DO- Dorsal oblique M.,DR- Dorsal rectus $M, M R-$ Medial rectus $M, L R$ - Lateral rectus $M, R P$ Retractor ocuuli M., LG- Lacrimal gland, ON- Optic N.

Fig (6): X- ray showing the arterial supply of the eye of the camel.

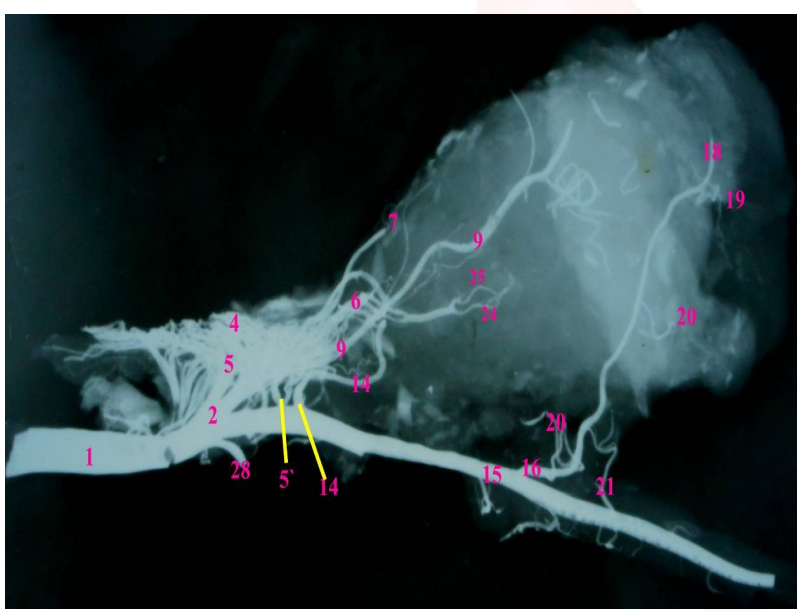

1- Maxillary A., 2- External ophthalmic A., 4- Epidural rete mirabile, 5- Rostral epidural rete mirabile, 6- Ophthalmic rete mirabile, 7- Supraorbital A, 9- Zygomaticotemporal A., 14- External ethmoidal A, 15- Infraorbital A, 16- Malar A, 17- Artery of third eyelid, 18- Medial superior palpebral A., 19- Medial inferior palpebral A., 20- Muscular branches, 21- Maxillary tubercular A, 24- Medial long posterior ciliary A., 25- Lateral long posterior ciliary A, 28- Buccal artery. foramen, it passed medially within the periorbita at the maxillary bone. It bifurcated into two branches, medial superior and medial inferior palpaberal arteries (Plate 3, Fig $6 / 16)$. The medial superior palpebral artery (A. Palpebralis
Plate (5): A photograph showing the branches of the infraorbital artery of the eye of the camel. A \& B- Right medial view, C- Right lateral view.

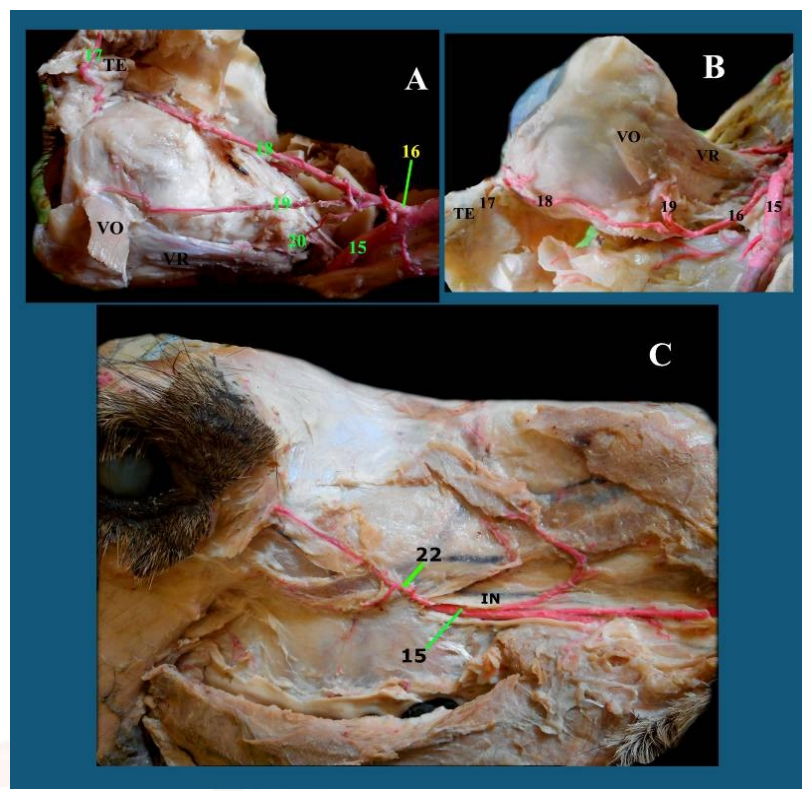

15- Infraorbital A., 16- Malar A, 17- Artery of third eyelid, 18- Medial superior palpebral A., 19- Medial inferior palpebral A., 20- Muscular branches, 22- Angular artery of the eye. TE- Third eyelid, VO- Ventral oblique,INInfraorbital N.

superior medialis) passed dorsally to the superior eyelid and anastomosed with the lateral superior palpebral one (Plate 5, Fig $6 / 18$ ) and detaching a wavy branch to the third eyelid called the artery of the third eyelid (Plate $5 / 17$ ). The medial inferior palpebral artery (A. Palpebralis inferior medialis) passed along the medial aspect of the ocular muscles and supply the ventral oblique muscle (Plate 5, 6 /19). A muscular branch emerged from the malar supplied the ventral rectus muscle (Plate 5, 6/20).

The maxillary tubercular artery detached just cranial to the malar artery, it was bifurcated into two muscular branches, perforated the ventral part of periorbita. It distributed to the ventral oblique muscle and medial rectus one (Plate 3, 6 /21).

The angular artery passed dorsally and caudally, along the maxillary bone and under the levator nasolabial muscle reached to the medial angle of the eye supplying the levator nasolibialis and malaris muscles (Plate 5 /22).

\section{DISCUSSION}

The arteries of the eye in dromedary camel were the branches derived from external ophthalmic artery, rostral epidural rete mirabile, external ethmoidal artery, the ophthalmic rete mirabile, 
the malar artery and maxillary tubercular one, in addition to the artery of the angle of the eye of the infraorbital artery, these results similar to [2] in dromedary camel and [5] in bacterin camel. The supraorbital artery derived from the dorsal aspect of external ophthalmic artery that's similar to [4] in dromedary camel, [9] and [10] in domestic animals, [11] in twin cattle. While [5] in bacterin camel stated that the supraorbital artery was a branch of the zygomaticotemporal artery. This study added that, the supraorbital artery was anastomosed with the external ethmoidal artery and the dorsal oblique muscular branch.

In this study no main lacrimal artery, only a 4-5 branches supplied the lacrimal gland, one branch of the external ophthalmic artery, 3-4 branches of zygomaticotemporal artery, one branch from these branches was passed around the contour of the lacrimal gland. That disagreement with [4] in dromedary camel,, [9] and [10] in domestic animals, [12] and [13] in dog who's reported a main lacrimal artery considered a continuation of the external ophthalmic artery. [13] in dog added that also could be arisen from the external ethmoidal artery.

In agreement with [5] in bacterin camel, the zygomaticotemporal artery was a branch of the external ophthalmic artery; it emerged 2-3 lacrimal branches, lateral superior palpaberal, lateral inferior palpaberal branches and some muscular branch. While the zygomaticotemporal artery was not reported by [4] in dromedary camel and [9] and [10] in domestic animals. The lateral superior and inferior palpebral artery were originated from the superficial temporal artery of the external carotid artery [9] in ox. The rostral epidural rete mirabile formed from the external ophthalmic and dorsal wall of maxillary artery that's similar to [14] in camel, [15] in bovine and [16] in Yak and Cattle. It terminated cranially by forming an ophthalmic rete mirabile that's gave off central retinal artery and two posterior long ciliaries arteries, While [9] in the ruminant stated that, the lacrimal artery originated from the ophthalmic rete, coursed along the optic nerve and gave off the anterior and posterior ciliaries arteries.

In agreement with [5] in bacterin camel, theexternal ethmoidal artery was originated from the maxillary artery, while [4] in dromedary camel and [9] in horse mentioned that, the external ethmoidal artery was the direct continuation of the external ophthalmic artery, and it originated from the supraorbital artery in ruminants. We added that the external ethmoid artery anastomosed with the supraorbital artery at the supraorbital foramen. .

The malar artery was the first branch of the infraorbital, giving off the medial superior palpebral, medial inferior palpebral and artery of the third eyelid, that's similar to [5] in bacterin camel, while it emerged by a common trunk with the infraorbital artery from the maxillary artery [4] in dromedary camel and in ruminants [9].

In agreement with [5] in bacterin camel, the maxillary tubercular artery was originated just rostral to the malar artery from the infraorbital, supplying the medial and ventral olique muscles. This artery was not observed by [4] in dromedary camel and [9] in all domestic animals.

In this study, the angular artery of the eye originated from the infraorbital artery just after emerging from the infraorbital foramen, that's similar to [5] in bacterin camel, while it arose from the malar artery in ruminants [9] and from the facial artery in equine $[9,10]$.

\section{Conflicts of Interests: None}

\section{REFERENCES}

[1]. Yam, B. A, and Khomeiri, M. Introduction to Camel origin, history, raising, characteristics, and wool, hair and skin: A Review. Journal of Agriculture and Environmental Management. 2015;4(11):496-508.

[2]. Kanan, C. V. Observations on the distribution of external and internal ophthalmic arteries in the camel (Camelus dromedarius). Acta Anatomica 1972;8:74-82.

[3]. Helmi Badwi, El- shaieb, M and Kenawy, A. The arteria maxilaris of the camel (Camelus dromedaries).Anatomia ,Histologia.Embryelogia 1977;6:21-28.

[4]. Smut, M. S. and Bezuidenhout, A. J. Anatomy of the Dromedary. Clarendon Press, 1987;146-151.

[5]. Wang, J, L. The arterial supply to the eye of the Bactrian camel (Camelus bactrianus). Veterinary research communication. 2002;26(7):505-512.

[6]. Cui, Sheng, Wang, j, and Xie, Z, M. The nerve supply to the orbit of Bactrian camel veterinary research communications 2004;28(1):7-15.

[7]. Abuagla, I, A, Ali, H, A, and Ibrahim, Z, H. An anatomical study on the eye of the one humped camel (Camelus dromedarius). Inter J Vet Sci, 2016;5(3):137-141. 
[8]. Frewein, J, and Habel, R. E. Nomina Anatomica Veterinaria 5th ed. Published By Committee On Vet. Anat. Nomenclature Of TheWorld Association Of Vet. Anatomists, Hannover.2012.

[9]. Getty, R. Sisson and Grossman's The Anatomy of the Domestic Animals. (5th ed). Philadelphia London Toronto: W. B. Saunders Company, 1975.

[10]. Dyce, K. M., Sack, W. O., and Wensing, C.J.G., Text book Of Veterinary Anatomy. 4th Ed. Saunders, 2010.

[11]. Fr'ckowiak, H, Szczepañska, K, Nabzdyk, M, Pawlak, $P$, and Zdun, M. Arteries of the head and encephalic base in a case of conjoined twin cattle, ACTA VET. BRNO 2016;85:003-007.

[12]. Park, S.A., Taylor, K.T., Zwingenberger, A.L., Reilly, C.M., Toupadakis, C.A., Marfurt, C.F., Good, K.L., Murphy, C.J. Gross anatomy and morphometric evaluation of the canine lacrimal and third eyelid glands. Vet Ophthalmol 2016;19:230-236.
[13]. Nesma I El-naseery, N, I, El-behery, E, I, El-Ghazali, H, $\mathrm{M}$, and El-Hady, E. The structural characterization of the lacrimal gland in the adult dog (Canis Familiaris, BENHA Veterinary medical journal 2016;31(2):106-116.

[14]. Jerbi, H, Khaldi, S. and Perez, W. Morphometric study of the rostral epidural rete mirabile in the dromedary (Camelus dromedarius, Linnaeus 1758). Int. J. Morphol., 2016;34(4):1429-1435.

[15]. Zdun, M, Fr'ckowiak, H, Kurc, A, K, Kowalczyk, K, Nabzdyk, M, and Timm, A. The Arteries of Brain Base in Species of Bovini Tribe, THE ANATOMICAL RECORD 2013;296:1677-1682.

[16]. Wang, X. R, Liu. Y, Zhang, L. P, Wang, X. J. and Wu, J. P. Comparative anatomical study of the epidural retia mirabile in the yak and cattle. Asian J. Anim. Vet. Adv., 2013;7(9):884-90.

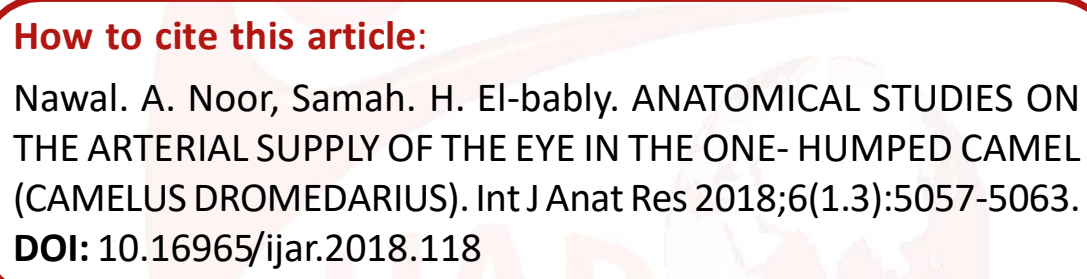

